\title{
Psychosis with propanolol: Still not recognized?
}

\author{
J.G. Cunnane and G.W. Blackwood
}

Department of Psychiatry, St. James' University Hospital, Beckett Street, Leeds LS9 7TF, UK.

\begin{abstract}
Summary: A 21 year old male developed hallucinations, personality change and severe depression following an increase in oral propranolol administration at recommended dosage levels. The symptoms improved markedly on stopping the drug. Without provocation, the patient developed further symptoms, mainly depressive, with marked suicidal impulses. Again, this quickly settled. The case identifies the need for careful observation of patients with psychiatric side effects from propranolol, following discontinuation of the drug.
\end{abstract}

\section{Introduction}

Propranolol is extensively used for a wide variety of conditions. Psychiatric side effects including visual hallucinations, ${ }^{1,2}$ auditory hallucinations, ${ }^{3}$ depression $^{4,5}$ and paranoid psychosis ${ }^{3}$ have been reported, but all have responded to withdrawal of the drug. The present report concerns a profound depression occurring shortly after the drug was discontinued in a patient presenting with a propranolol-induced psychosis. This serious reaction has not been described before.

\section{Case report}

A 21 year old man with a 10-year history of migraine was treated with oral propanolol $80 \mathrm{mg}$ twice daily for 9 months. This gave inadequate prophylaxis and the dose was therefore increased to $80 \mathrm{mg}$ three times daily. No further attacks occurred. After 6 weeks at the higher dose he began to experience visual hallucinations involving spiders, auditory hallucinations in which a voice whispered his name, vivid, recurrent nightmares, depressed mood with suicidal impulses, and personality change with odd behaviour and violent outbursts. One of these outbursts occurred at work when he pushed a colleague from the cab of an excavator in a quarry, with potentially tragic consequences. On another occasion he noticed that he was being 'flashed' by other drivers on a motorway, only to find that, to his surprise, he had been driving along at 20 miles per hour without realizing it. He had no previous psychiatric history and an even-tempered, outgoing premorbid personality.

On admission to hospital the propranolol was

Correspondence: J.G. Cunnane, M.B.Ch.B.

Accepted: 31 July 1986 stopped and his symptoms improved markedly within 48 hours. Physical examination was normal, and no other medication was given. Electroencephalogram and skull radiograph were normal, as were routine haematological and biochemical investigations. He remained improved for 5 more days before discharge. His only residual symptoms were a slight loss of confidence, and a seeking for reassurance that he would remain well.

He was admitted 9 days later with pervasive anhedonia, decreased appetite, depressed mood and a preoccupation with death and suicide. He admitted to suicidal impulses and would fantasize that he was hanging from the ceiling. He again complained of visual hallucinations, this time seeing a five-bar wooden gate across his bedroom doorway. A further electroencephalogram was normal, and he was treated with haloperidol $5 \mathrm{mg}$ twice daily. Within a week he was considerably better, his depression had lifted, the suicidal impulses had ceased, and the hallucinations had stopped. He was then discharged on no medication and has remained symptom-free during 6 months of follow-up.

\section{Discussion}

Propranolol has long been reported as the cause of psychiatric side effects, ${ }^{4,6}$ although this has been subject to some dispute in recent years. ${ }^{7}$ Further evidence $^{5,8}$ clearly suggests a causative role for propranolol, and the present report supports this view. Of particular interest in this case is the potentially tragic incident in which the patient pushed a fellow worker out of the cab of his excavator, and could have killed him. The forensic implications are clear. Of further interest is the recurrence of psychosis following 
discontinuation of the drug. This phenomenon has not been previously described, although Pollack et al. ${ }^{8}$ report the recurrence of depression. It might be held that this case could represent a first episode of paranoid schizophrenia, but this is made unlikely by the absence of first-rank symptoms, the presence of visual hallucinations, and the rapid, complete recovery.

Propranolol is a $\beta$-adrenergic receptor antagonist

\section{References}

1. Fleminger, R. Visual hallucinations and illusions with propranolol. Br Med J 1978, 1: 1182.

2. White, W.B. \& Riotte, K. Propranolol and white rabbits. N Engl J Med 1982, 307: 558-559.

3. Gershon, E.S., Goldstein, R.E., Moss, A.J. \& van Kammen, D.P. Psychosis with ordinary doses of propranolol. Ann Intern Med 1979, 90: 938-939.

4. Waal, H.J. Propranolol induced depression. $\mathrm{Br}$ Med J 1967, 2: 50.

5. Petrie, W. \& Maffucci, R. Propranolol and depression. Am J Psychiat 1982, 139: 92-94. which is strongly lipophilic and known to be centrally active in man. Although psychiatric side effects have been reported for nearly 20 years, and are recognized $Q$ by the manufacturers in the USA, they do not appear

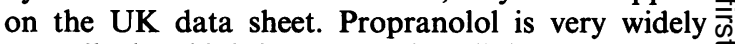
prescribed and it is important that clinicians be awareof the full range of psychiatric morbidity associated with this drug.

6. Stephen, S.A. Unwanted effects of propranolol. Am $J \vec{\omega}$ Cardiol 1966, 18: 463-468.

7. Paykel, E., Fleminger, M.B. \& Watson, J. Psychiatric side-effects of antihypertensive drugs other than reserpine. Clin Psychopharmacol 1982, 2: 14-39.

8. Pollack, M.H., Rosenbaum, J.F. \& Cassam, N.H. Propranolol and depression revisited; three cases and a review. J Nerv Ment Dis 1985, 173: 118-119. 